\title{
Biaya Operasional Sepeda Motor Matic Dan Manual
}

\author{
Meidia Refiyanni* ${ }^{* 1}$, Muhammad Ikhsan ${ }^{2}$ \\ ${ }^{1,2}$ Jurusan Teknik Sipil Universitas Teuku Umar, Alue Penyareng, Meulaboh, Aceh Barat \\ e-mail: ${ }^{\text {"1 }}$ refiyannim@gmail.com, ${ }^{2}$ m.ikhsan@utu.ac.id
}

\begin{abstract}
Abstrak
Penelitian ini dilakukan untuk mengetahui perbandingan biaya operasional sepeda motor roda dua antara matic dan manual. Menentukan model yang memadai untuk biaya operasional kendaraan bermotor roda dua, menganalisis dan mengidentifikasi faktor-faktor yang berpengaruh terhadap biaya operasional kendaraan bermotor roda dua di Desa Blang Puuk Kecamatan Seunagan. Dalam penelitian ini dilakukan pengujian statistik, yang meliputi analisis koefisien korelasi, regresi linear berganda, analisis koefisien determinasi $\left(R^{2}\right)$, uji $T$ dan uji $F$ terhadap variabel terikat (dependent) dan variabel bebas (independent). Dalam melakukan pengujian statistik, pengolahan datanya menggunakan bantuan software SPSS (Statistical Product and Service Solution) versi 23. Kemudian setelah dilakukan pengujian statistik dilanjutkan dengan menghitung biaya operasional kendaraan berdasarkan jenis, kapasitas, dan tahun perakitan yang meliputi biaya tetap (fixed cost) dan biaya variabel (variabel cost). Dari hasil penelitian diperoleh model analisis Biaya Operasional Kendaraan (BOK) roda dua di Desa Blang Puuk adalah $Y=11,167+0,004 X_{1}+$ $0,001 X_{2}+0,000 X_{3}+0,002 X_{4}-0,003 X_{5}+0,001 X_{6}+0,001 X_{7}+3,905 X_{8}$. Adapun faktor yang paling dominan berpengaruh terhadap perjalanan dalam hal ini biaya operasionalnya yaitu pemakaian bahan bakar. Biaya Operasional Kendaraan (BOK) total maksimum tiap $1 \mathrm{~km}$ perjalanan yaitu: kendaraan dengan kapasitas 100 CC (jenis bebek) tahun perakitan 2004-2009 yaitu sebesar Rp. 865,75; kapasitas 125 CC (jenis bebek) tahun perakitan 2004-2009 dan 2010-2015 yaitu sebesar Rp. 674,78 dan 605,57; kapasitas 110 CC (jenis skuter matic) tahun perakitan 2004-2009 dan 2010-2015 yaitu sebesar Rp. 570,88 dan Rp. 995,05; kapasitas 115 CC (jenis skuter matic) tahun perakitan 2004-2009 dan 2010-2015 yaitu sebesar Rp629,60 dan $\operatorname{Rp} 762,96$.
\end{abstract}

Kata Kunci: Pemodelan, BOK, Kendaraan, SPSS

\begin{abstract}
This research was conducted to find out the comparison of operational cost of motorcycle between matic and manual. Determining adequate model for operational cost of two-wheeled motor vehicle, analyzing and identifying factors influencing operational cost of two-wheeled vehicles in Blang Puuk Village, Seunagan Sub-district. In this research, the statistical test, which includes correlation coefficient analysis, multiple linear regression, coefficient of determination $(R 2), T$ test and $F$ test of dependent variable and independent variable. In performing statistical tests, data processing uses SPSS (Statistical Product and Service Solution) software version 23. Then after statistical tests continued by calculating the operational cost of vehicles based on type, capacity, and assembly year which includes fixed cost and cost variable (variable cost). The result of the research shows that the analysis model of Vehicle Operating Cost (BOK) of two wheel in Blang Punk Village is $Y=11,167+0,004 X 1+0,001 X 2+0,000 X 3+0,002 X 4-0,003 X 5+0,001 X \neg 6+0,001 X 7+$ 3,905X8. The most dominant factor influences travel in this case the operational cost is the use of fuel. Maximum Vehicle Operational Cost (BOK) for every $1 \mathrm{~km}$ of travel: vehicles with capacity of 100 CC (duck type) of 2004-2009 assembly year which is Rp. 865.75; capacity of 125 CC (duck type) of assembly year 2004-2009 and 2010-2015 amounting to Rp. 674,78 and 605,57; capacity 110 CC (scooter matic type) assembly year 2004-2009 and 2010-2015 that is equal to Rp. 570,88 and Rp. 995,05; capacity 115 CC (scooter matic type) assembly year 2004-2009 and 2010-2015 that amounted to Rp. 629, 60 and Rp. 762, 96.
\end{abstract}

Keywords: Modeling, BOK, Vehicle, SPSS 


\section{PENDAHULUAN}

$\mathbf{M}$ eningkatnya keadaan ekonomi maka kebutuhan akan sarana transportasi dalam melakukan perjalanan juga semakin meningkat. Memiliki sarana transportasi sendiri masyarakat akan tidak tergantung kepada angkutan umum jika akan melakukan perjalanan ke suatu tempat tertentu. Dalam memilih sarana transportasi disamping dipengaruhi oleh kemampuan ekonomi juga dipengaruhi oleh selera pengguna. Masyarakat di Kota Nagan Raya banyak yang berasal dari tingkat ekonomi menengah sehingga yang memiliki kendaraan bermotor roda dua lebih banyak dari pada yang beroda empat. Dengan demikian kendaraan bermotor roda dua (sepeda motor) mendominasi pengguna jalan hingga untuk menganalisis kelayakan suatu proyek jalan moda sepeda motor harus dipertimbangkan.

Warsiti (2003), transportasi yaitu pemindahan barang dan manusia dari tempat asal ke tempat tujuan, atau transportasi adalah perpindahan dari suatu tempat ke tempat lain dengan menggunakan alat pengangkutan, baik yang digerakkan oleh tenaga manusia, hewan (kuda, sapi, kerbau), atau mesin. Konsep transportasi didasarkan pada adanya perjalanan (trip) antara asal (origin) dan tujuan (destination). Di dalam transportasi, terdapat unsur-unsur yang terkait erat dalam berjalannya konsep transportasi itu sendiri. Unsur-unsur tersebut adalah sebagai berikut: manusia yang membutuhkan; barang yang dibutuhkan; kendaraan sebagai alat/sarana; jalan dan terminal sebagai prasarana transportasi; dan organisasi (pengelola transportasi).

Analisis data dilakukan dalam rangka membangun model BOK sepeda motor khususnya bagi biaya administrasi, biaya servis berat dan ringan, biaya ban, dan biaya pemakaian oli. Dalam hal ini, berbagai pendekatan model, mulai dari model linier maupun model non-linier dianalisis untuk menemukan model-model BOK terbaik sesuai data yang ada. Hasil-hasil pemodelan berbagai komponen BOK tersebut dapat dipergunakan dalam mengestimasi besaran BOK sepeda motor di Kota Nagan Raya. Maka untuk itu Penulis melakukan survei penelitian terhadap responden pengguna kendaraan bermotor roda dua yang merupakan penduduk yang berdomisili di Desa Blang Puuk Kecamatan Seunagan Timur Kabupaten Nagan Raya.

\section{METODOLOGI PENELITIAN}

\section{Lokasi Penelitian}

Lokasi yang menjadi wilayah dalam penelitian ini adalah Kota Nagan Raya. Penelitian dilakukan dengan cara survei terhadap responden pemilik kendaraan bermotor roda dua yang berada di Desa Blang Puuk Kecamatan Seunagan dengan mengajukan kuesioner mengenai biaya operasi kendaraan roda dua (sepeda motor). Adapun peta lokasi proyek dapat dilihat pada lampiran A.1.1 halaman 29.

\section{Pengumpulan Data}

Sampel atau contoh adalah sebagian dari populasi yang karakteristiknya hendak diteliti. Dalam melakukan penelitian analisis BOK roda dua tau sepeda motor, data yang diperlukan adalah data primer dan data sekunder. Data primer diperoleh secara langsung dengan cara wawancara atau kuesioner terhadap pengguna atau pemilik kendaraan roda dua atau sepeda motor dengan terlebih dahulu peneliti membuat data kuesioner. 
Vol. 4 No.1 April 2018

pp. 85 - 95

Data Primer

Menurut Warsiti (2003), adapun data primer yang diperlukan yaitu:

1. Jumlah pemakaian bbm;

2. Jumlah pemakaian oli;

3. Rentang waktu pergantian ban;

4. Rentang waktu pelaksanaan servis;

5. Biaya suku cadang;

6. Biaya tak terduga;

Data sekunder

Data sekunder diperoleh dari instansi seperti samsat, dealer kendaraan, SPBU (Stasiun Pengisian Bahan Bakar Umum), toko onderdil atau suku cadang sepeda motor di daerah Meulaboh. Adapun data sekunder yang diperlukan antara lain:

1. Nilai jual kendaraan dari samsat;

2. Besarnya pajak yang dibayar dari samsat;

3. Harga bahan bakar, oli samping, oli mesin dari SPBU;

4. Biaya servis dari dealer atau bengkel sepeda motor.

\section{Metode Analisis Data}

Data-data yang diperoleh dari survei selanjutnya diekstraksi dalam bentuk tabulasi sesuai dengan jenis-jenis biaya operasional kendaraan sepeda motor, seperti tahun produksi, pemakaian bahan bakar minyak (BBM), biaya servis ringan, biaya servis berat, biaya pemakaian ban, lama pemakaian ban biaya pergantian oli, dan lain-lain. Pentabulasian dan pengklasifikasian data sesuai dengan jenis-jenis BOK sepeda motor tersebut. Hasil tabulasi dianalisis sesuai dengan kategori tahun dan usia sepeda motor. Selanjutnya hasil analisis dan ekstraksi tersebut dimodelkan dengan menggunakan berbagai pendekatan regresi lainnya seperti model linier, koefesien kolerasi, koefesien determinan $\left(\mathrm{R}^{2}\right)$, Uji T, Uji F.

\section{HASIL DAN PEMBAHASAN}

\section{Sampel}

Dalam penelitian ini sampel yang diambil adalah penduduk daerah Blang Puuk yang berada di Kecamatan Seunagan yang terdiri dari 146 KK (Kepala Keluarga) dengan jumlah penduduk dewasa 327 orang penduduk. Sampel yang baik, yang kesimpulannya dapat dikenakan pada populasi adalah sampel yang bersifat representatif atau yang dapat menggambarkan karakteristik populasi.

Dengan mengadopsi rumus pada bab dua serta galat pendugaan (10\%) maka dapat dihitung jumlah sampel sebagai berikut:

$$
\begin{aligned}
& \mathrm{n}=\frac{\mathrm{N}}{\mathrm{N} \cdot \mathrm{d}^{2}+1} \\
& \mathrm{n}=\frac{327}{327 \cdot(0,1)^{2}+1} \\
& \mathrm{n}=\frac{327}{4,27}=76,58 \text { sampel }
\end{aligned}
$$


Jumlah sampel yang diteliti adalah 76,58 sampel, untuk memudahkan dalam pengolahan data maka penulis membulatkan menjadi 77 sampel.

\section{Pengujian Statistik}

Dari data yang diperoleh melalui kuesioner, model formulasi perjalanan menggunakan formula regression dengan menggunakan bantuan software SPSS 23. Adapun data yang digunakan adalah variabel terikat $\mathrm{Y}$ (dependent) dan variabel bebas X (independent). Dari masing-masing kelompok dilakukan analisis statistik dalam bentuk regresi hubungan dari masing-masing variabel terikat (dependent) yaitu perjalanan dalam hal ini Biaya Operasional Kendaraan (BOK) dengan variabel bebas (independent) yang meliputi pemakaian bahan bakar, pemakaian oli, pergantian ban, servis, suku cadang dan biaya tak terduga.

\section{Analisis Koefisien Korelasi}

Korelasi di Desa Blang Puuk Kecamatan Seunagan, variabel dependentnya adalah perjalanan, sedangkan pemakaian bahan bakar, pemakaian oli mesin, pemakaian oli transmisi/gear, pergantian ban luar, pergantian ban dalam, pelaksanaan servis, biaya suku cadang dan biaya tak terduga merupakan variabel independent. Hasil perhitungan korelasi antara variabel dependent dan variabel independent dapat dilihat pada tabel 4.9 di berikut ini.

Tabel1. Perhitungan Korelasi dengan Software SPSS

\begin{tabular}{|c|c|c|c|c|c|c|c|c|c|c|}
\hline & & $\mathrm{Y}$ & $\mathrm{X} 1$ & $\mathrm{X} 2$ & $\mathrm{X} 3$ & $\mathrm{X} 4$ & $\mathrm{X} 5$ & X6 & $\mathrm{X} 7$ & $\mathrm{X} 8$ \\
\hline \multirow{9}{*}{$\begin{array}{l}\text { Person } \\
\text { Correlation }\end{array}$} & Perjalanan & 1.000 & .974 & .404 & .103 & .057 & -.286 & .136 & .382 & -.021 \\
\hline & BBM & .974 & 1.000 & .369 & .083 & .034 & .274 & .092 & .333 & -.028 \\
\hline & Oli mesin & .404 & .369 & 1.000 & .370 & .122 & -.339 & .272 & .425 & -.046 \\
\hline & Oli gear & .103 & .083 & .370 & 1.000 & -.212 & -.266 & .323 & .225 & .167 \\
\hline & Ban luar & .057 & .034 & .122 & -.212 & 1.000 & .325 & .133 & .043 & -.107 \\
\hline & ban dalam & -.286 & -.274 & -.339 & -.266 & .325 & 1.000 & -.126 & -.223 & .103 \\
\hline & Servis & -.136 & .092 & .272 & .323 & .133 & -.126 & 1.000 & .269 & .001 \\
\hline & $\begin{array}{l}\text { Suku } \\
\text { cadang }\end{array}$ & .382 & .333 & .425 & .225 & .043 & -.223 & .269 & 1.000 & -.010 \\
\hline & $\begin{array}{l}\text { Tak } \\
\text { terduga }\end{array}$ & -.021 & -.028 & -.046 & .167 & -.107 & .103 & .001 & -.010 & 1.000 \\
\hline \multirow{9}{*}{$\begin{array}{l}\text { Sig. (1- } \\
\text { tailed) }\end{array}$} & Perjalanan & & .000 & .000 & .186 & .310 & .006 & .120 & . 000 & .428 \\
\hline & BBM & .000 & & .000 & .237 & .386 & .008 & .214 & .002 & .405 \\
\hline & Oli mesin & .000 & .000 & & .000 & .145 & .001 & .008 & .000 & .345 \\
\hline & Oli gear & .186 & .237 & .000 & 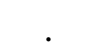 & .032 & .010 & .002 & .024 & .073 \\
\hline & Ban luar & .310 & .386 & .145 & .032 & & .002 & .124 & .356 & .176 \\
\hline & ban dalam & .006 & .008 & .001 & .010 & .002 & & .137 & .026 & .186 \\
\hline & Servis & .120 & .214 & .008 & .002 & .124 & .137 & 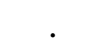 & .009 & .497 \\
\hline & $\begin{array}{l}\text { Suku } \\
\text { cadang }\end{array}$ & .000 & .002 & .000 & .024 & .356 & .026 & .009 & . & .464 \\
\hline & $\begin{array}{l}\text { Tak } \\
\text { terduga }\end{array}$ & .428 & .405 & .345 & .073 & .176 & .186 & .497 & .464 & . \\
\hline Total & $\mathrm{N}$ & 77 & 77 & 77 & 77 & 77 & 77 & 77 & 77 & 77 \\
\hline
\end{tabular}

Dari tabel di atas dapat dilihat hasil perhitungan koefisien korelasi pada kolom Person Correlation yang merupakan besarnya nilai persentase hubungan antara variabel $\mathrm{X}$ dengan variabel Y. 


\section{Regresi Linier Berganda}

Analisis regresi linier berganda ini digunakan untuk mengetahui ada atau tidaknya hubungan dari variabel independent terhadap variabel dependent. Dalam hal analisis Biaya Operasional Kendaraan (BOK), analisis regresi linier dilakukan terhadap biaya variabel. Berikut ini tabel 4.11 merupakan hasil dari uji regresi linier berganda dengan menggunakan software SPSS 23.

Tabel 2. Perhitungan Regresi Linier Berganda dengan Software SPSS

\begin{tabular}{|c|c|c|c|c|c|c|}
\hline \multirow{2}{*}{\multicolumn{2}{|c|}{ Model }} & \multicolumn{2}{|c|}{$\begin{array}{l}\text { Unstandardized } \\
\text { Coefficient }\end{array}$} & \multirow{2}{*}{$\begin{array}{c}\begin{array}{c}\text { Standardized } \\
\text { Coefficient }\end{array} \\
\text { Beta }\end{array}$} & \multirow[t]{2}{*}{$\mathrm{t}$} & \multirow[t]{2}{*}{ Sig. } \\
\hline & & B & Std. Error & & & \\
\hline 1 & (Constans) & 11.167 & 6.708 & & 1.665 & .101 \\
\hline & BBM & .004 & .000 & .943 & 32.578 & .000 \\
\hline & Oli mesin & .001 & .001 & .023 & .692 & .491 \\
\hline & Oli gear & .000 & .003 & -.004 & -.121 & .904 \\
\hline & Ban luar & .002 & .002 & .022 & .752 & .455 \\
\hline & Ban dalam & -.003 & .006 & -.015 & -.477 & .635 \\
\hline & Servis & .001 & .001 & .027 & .930 & .356 \\
\hline & Suku cadang & .001 & .000 & .048 & 1.610 & .112 \\
\hline & Tak terduga & 3,905 & .000 & .011 & .420 & .676 \\
\hline
\end{tabular}

Berdasarkan tabel di atas diperoleh model persamaan regresi linier berganda, yaitu sebagai berikut ini:

$$
\begin{aligned}
\mathrm{Y}= & 11,167+0,004 \mathrm{X}_{1}+0,001 \mathrm{X}_{2}+0,000 \mathrm{X}_{3}+0,002 \mathrm{X}_{4}-0,003 \mathrm{X}_{5}+ \\
& 0,001 \mathrm{X}_{6}+0,001 \mathrm{X}_{7}+3,905 \mathrm{X}_{8}
\end{aligned}
$$

Dimana:
$\mathrm{Y}=$ Banyaknya perjalanan
$\mathrm{X}_{1}=\quad$ Pemakaian bahan bakar
$\mathrm{X}_{2}=$ pemakaian oli mesin
$\mathrm{X}_{3}=$ pemakaian oli transmisi/gear
$\mathrm{X}_{4}=$ pergantian ban luar
$\mathrm{X}_{5}=\quad$ Pergantian ban dalam
$\mathrm{X}_{6}=$ pelaksanaan servis
$\mathrm{X}_{7}=$ biaya suku cadang
$\mathrm{X}_{8}=\quad$ Biaya tak terduga

\section{Analisis Koefisien Determinasi $\left(\mathbf{R}^{2}\right)$}

Analisis koefisien determinasi menjelaskan besarnya nilai pengaruh variabel-variabel bebas (independent) terhadap variabel terikat (dependent). Atau dapat pula dikatakan sebagai proporsi pengaruh seluruh variabel bebas terhadap variabel terikat. Nilai koefisien determinasi dapat diukur oleh nilai $\mathrm{R}$ Square atau Adjusted $\mathrm{R}$ Square. Hasil perhitungan dari koefisien determinasi menggunakan software SPSS dapat dilihat pada tabel 4.12 di berikut ini.

Tabel 3. Perhitungan Koefisien Determinasi $\left(\mathrm{R}^{2}\right)$ dengan Software SPSS

\begin{tabular}{|c|c|c|c|c|}
\hline Model & $\mathrm{R}$ & $\begin{array}{c}\mathrm{R} \\
\text { Square }\end{array}$ & $\begin{array}{c}\text { Adjusted R } \\
\text { Square }\end{array}$ & Std. Error oh the Estimate \\
\hline 1 & $.977^{\mathrm{a}}$ & .955 & .949 & 6,054 \\
\hline
\end{tabular}


Berdasarkan tabel di atas dapat dilihat bahwa output SPSS memiliki nilai Adjusted $R$ Square sebesar 0,949. Hal ini menunjukkan bahwa proporsi pengaruh variabel bebas (independent) yaitu pemakaian bahan bakar, pemakaian oli mesin, pemakaian oli transmisi/gear, pergantian ban luar, pergantian ban dalam, pelaksanaan servis, biaya suku cadang dan biaya tak terduga terhadap variabel terikat (dependent) sebesar 94,9\%. Sedangkan sisanya 5,1\% (100\% - 94,9\%) dipengaruhi oleh variabel lain yang tidak dijelaskan dalam model regresi linier pada penelitian ini.

\section{Perhitungan Biaya Operasional Kendaraan (BOK)}

Biaya Operasional Kendaraan (BOK) roda dua/sepeda motor dihitung berdasarkan biaya tetap (fixed cost) dan biaya variabel (variable cost). Untuk biaya-biaya variabel dimasukkan ke dalam model persamaan regresi linier berganda, yaitu $Y=11,167+0,004 X_{1}+0,001 X_{2}+0,000 X_{3}$ $+0,002 X_{4}-0,003 X_{5}+0,001 X_{6}+0,001 X_{7}+3,905 X_{8}$.

Berdasarkan BOK dihitung untuk setiap 1 (satu) kilometer perjalanan berdasarkan jenis, kapasitas dan tahun perakitannya. BOK rata-rata dapat dilihat pada tabel 4.29 berikut ini.

Tabel 4 BOK Total Rata-rata Tiap $1 \mathrm{Km}$

\begin{tabular}{|c|c|c|c|c|c|}
\hline \multirow{3}{*}{ Uraian/ Tahun Perakitan } & \multirow{3}{*}{ Uraian/ Tahun Perakitan } & \multicolumn{4}{|c|}{ Kapasitas/Tipe (Rp) } \\
\hline & & $100 \mathrm{CC}$ & $125 \mathrm{CC}$ & $110 \mathrm{CC}$ & $115 \mathrm{CC}$ \\
\hline & & \multicolumn{2}{|c|}{ Bebek } & \multicolumn{2}{|c|}{ Skuter Matic } \\
\hline \multirow{15}{*}{ 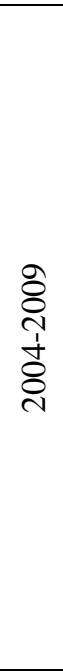 } & Biaya Tetap (FC) & & & & \\
\hline & Depresiasi & 120,42 & 70,94 & 61,47 & 75,88 \\
\hline & Pajak & 17,82 & 22,05 & 15,56 & 15,35 \\
\hline & Jumlah FC & 138,24 & 92,99 & 77,03 & 91,23 \\
\hline & Biaya Variabel (VC) & \multicolumn{4}{|c|}{$\begin{array}{c}\mathrm{Y}=11,167+0,004 \mathrm{X}_{1}+0,001 \mathrm{X}_{2}+0,000 \mathrm{X}_{3}+0,002 \mathrm{X}_{4}- \\
0,003 \mathrm{X}_{5}+0,001 \mathrm{X}_{6}+0,001 \mathrm{X}_{7}+3,905 \mathrm{X}_{8}\end{array}$} \\
\hline & Bahan Bakar (X1) & 206,12 & 208,60 & 211,11 & 204,69 \\
\hline & Oli Mesin (X2) & 11,78 & 14,60 & 11,46 & 14,26 \\
\hline & Oli Transmisi/Gear (X3) & - & - & 2,91 & 2,95 \\
\hline & Ban Luar (X4) & 10,97 & 10,33 & 7,55 & 7,23 \\
\hline & Ban Dalam (X5) & 4,32 & 4,25 & 2,74 & 2,43 \\
\hline & Servis (X6) & 22,24 & 21,56 & 22,97 & 29,08 \\
\hline & Suku Cadang (X7) & 48,89 & 52,43 & 47,01 & 50,68 \\
\hline & Tak Terduga (X8) & 166,29 & 121,80 & 110,76 & 121,35 \\
\hline & Jumlah (VC) & 470,61 & 433,57 & 416,51 & 432,67 \\
\hline & TOTAL $(\mathrm{FC}+\mathrm{VC})$ & 608,85 & 526,56 & 493,54 & 523,90 \\
\hline \multirow{15}{*}{ 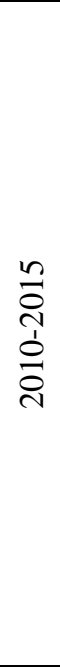 } & Biaya Tetap (FC) & & & & \\
\hline & Depresiasi & - & 72,90 & 132,20 & 125,21 \\
\hline & Pajak & - & 18,12 & 19,21 & 18,48 \\
\hline & Jumlah FC & - & 91,20 & 151,41 & 143,69 \\
\hline & Biaya Variabel (VC) & \multicolumn{4}{|c|}{$\begin{array}{c}\mathrm{Y}=11,167+0,004 \mathrm{X}_{1}+0,001 \mathrm{X}_{2}+0,000 \mathrm{X}_{3}+0,002 \mathrm{X}_{4}- \\
0,003 \mathrm{X}_{5}+0,001 \mathrm{X}_{6}+0,001 \mathrm{X}_{7}+3,905 \mathrm{X}_{8}\end{array}$} \\
\hline & Bahan Bakar (X1) & - & 214,68 & 205,45 & 204,93 \\
\hline & Oli Mesin (X2) & - & 11,76 & 16,63 & 14,90 \\
\hline & Oli Transmisi/Gear (X3) & - & - & 3,48 & 3,74 \\
\hline & Ban Luar (X4) & - & 9,81 & 9,35 & 9,90 \\
\hline & Ban Dalam (X5) & - & 3,02 & 3,54 & 3,91 \\
\hline & Servis (X6) & - & 18,90 & 25,84 & 25,78 \\
\hline & Suku Cadang (X7) & - & 41,44 & 54,89 & 48,61 \\
\hline & Tak Terduga (X8) & - & 107,86 & 188,27 & 88,51 \\
\hline & Jumlah (VC) & - & 407,47 & 507,45 & 400,28 \\
\hline & TOTAL $(\mathrm{FC}+\mathrm{VC})$ & - & 498,49 & 658,86 & 543,9 \\
\hline
\end{tabular}


Vol. 4 No.1 April 2018

pp. 85 - 95

Untuk mengetahui BOK total maksimum menurut jenis, kapasitas dan tahun perakitannya dapat dilihat pada tabel 4.30 berikut ini.

Tabel 5. BOK Total Maksimum Tiap $1 \mathrm{Km}$

\begin{tabular}{|c|c|c|c|c|c|}
\hline \multirow{3}{*}{\multicolumn{2}{|c|}{ Uraian/ Tahun Perakitan }} & \multicolumn{4}{|c|}{ Kapasitas/Tipe (Rp) } \\
\hline & & $100 \mathrm{CC}$ & $125 \mathrm{CC}$ & $110 \mathrm{CC}$ & $115 \mathrm{CC}$ \\
\hline & & \multicolumn{2}{|c|}{ Bebek } & \multicolumn{2}{|c|}{ Skuter Matic } \\
\hline \multirow{15}{*}{ 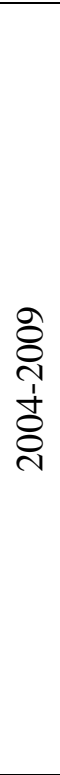 } & Biaya Tetap (FC) & & & & \\
\hline & Depresiasi & 228,37 & 104,17 & 71,23 & 92,59 \\
\hline & Pajak & 23,52 & 24,23 & 18,59 & 17,31 \\
\hline & Jumlah FC & 251,89 & 128,40 & 89,82 & 109,90 \\
\hline & Biaya Variabel (VC) & \multicolumn{4}{|c|}{$\begin{array}{c}\mathrm{Y}=11,167+0,004 \mathrm{X}_{1}+0,001 \mathrm{X}_{2}+0,000 \mathrm{X}_{3}+ \\
0,002 \mathrm{X}_{4}-0,003 \mathrm{X}_{5}+0,001 \mathrm{X}_{6}+0,001 \mathrm{X}_{7}+3,905 \mathrm{X}_{8}\end{array}$} \\
\hline & Bahan Bakar (X1) & 218,75 & 218,75 & 222,22 & 218,75 \\
\hline & Oli Mesin (X2) & 24,31 & 23,89 & 12,50 & 18,75 \\
\hline & Oli Transmisi/Gear (X3) & - & - & 3,47 & 4,17 \\
\hline & Ban Luar (X4) & 13,68 & 13,68 & 9,62 & 9,01 \\
\hline & Ban Dalam (X5) & 5,61 & 4,81 & 2,49 & 2,99 \\
\hline & Servis (X6) & 44,44 & 47,62 & 33,33 & 41,67 \\
\hline & Suku Cadang (X7) & 89,74 & 76,92 & 64,10 & 57,69 \\
\hline & Tak Terduga (X8) & 208,33 & 160,71 & 133,33 & 166,67 \\
\hline & Jumlah (VC) & 604,86 & 546,38 & 481,06 & 519,7 \\
\hline & TOTAL $(\mathrm{FC}+\mathrm{VC})$ & 856,75 & 674,78 & 570,88 & 629,60 \\
\hline \multirow{15}{*}{ 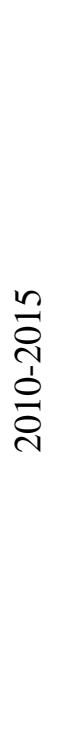 } & Biaya Tetap (FC) & & & & \\
\hline & Depresiasi & - & 111,11 & 243,59 & 230,77 \\
\hline & Pajak & - & 23,65 & 25,72 & 23,56 \\
\hline & Jumlah FC & - & 134,76 & 269,31 & 254,33 \\
\hline & Biaya Variabel (VC) & \multicolumn{4}{|c|}{$\begin{array}{c}\mathrm{Y}=11,167+0,004 \mathrm{X}_{1}+0,001 \mathrm{X}_{2}+0,000 \mathrm{X}_{3}+ \\
0,002 \mathrm{X}_{4}-0,003 \mathrm{X}_{5}+0,001 \mathrm{X}_{6}+0,001 \mathrm{X}_{7}+3,905 \mathrm{X}_{8}\end{array}$} \\
\hline & Bahan Bakar (X1) & - & 222,22 & 218,75 & 222,22 \\
\hline & Oli Mesin (X2) & - & 14,33 & 35,16 & 25,00 \\
\hline & Oli Transmisi/Gear (X3) & - & - & 5,21 & 5,00 \\
\hline & Ban Luar (X4) & - & 13,68 & 12,82 & 12,82 \\
\hline & Ban Dalam (X5) & - & 3,74 & 5,61 & 4,49 \\
\hline & Servis (X6) & - & 26,67 & 55,56 & 41,67 \\
\hline & Suku Cadang (X7) & - & 51,28 & 80,13 & 64,10 \\
\hline & Tak Terduga (X8) & - & 138,89 & 312,50 & 133,33 \\
\hline & Jumlah (VC) & - & 470,81 & 725,74 & 508,63 \\
\hline & TOTAL $(\mathrm{FC}+\mathrm{VC})$ & - & 605,57 & 995,05 & 762,96 \\
\hline
\end{tabular}

\section{Pembahasan}

Dari data yang diperoleh ditentukan variabel terikat (dependent) dan variabel bebas (independent). Dalam hal ini, perjalanan merupakan variabel terikat (dependent) sedangkan pemakaian bahan bakar, pemakaian oli, pergantian ban, servis, biaya suku cadang dan biaya tak terduga termasuk variabel bebas (independent). Pada pembahasan ini dijelaskan tentang faktor yang mendominasi yang mempengaruhi perjalanan yaitu biaya operasional kendaraan (BOK), 
model analisis perjalanan dan biaya total operasional tersebut berdasarkan jenis, kapasitas dan tahun perakitannya.

Faktor Dominasi yang Mempengaruhi Biaya Operasional Kendaraan (BOK) sepeda motor

Uji t dari analisis regresi linier berganda yang perhitungannya menggunakan software SPSS 23 dilakukan untuk mengetahui faktor-faktor apa saja (variabel bebas $X_{n}$ ) yang mempunyai pengaruh secara persial dan signifikan terhadap perjalanan (variabel trikat Y) dalam hal ini biaya operasional kendaraan (BOK). Dari hasil perhitungan uji t tersebut diperoleh bahwa:

Nilai $t_{\text {hitung }}$ variabel biaya pemkaian bahan bakar $\left(X_{1}\right)$ sebesar 32,578 lebih besar dari nilai $t_{\text {tabel }}$ yaitu sebesar 1,665. Sedangkan probabilitasnya Sig $_{\text {hitung }}$ sebesar 0,000 lebih kecil dari 0,05 (derajat siginifikan tingkat kesalahan yang ditentukan). Maka variabel bebas $\mathrm{X}_{1}$ berpengaruh secara parsial dan signifikan terhadap variabel terikat Y.

Maka dapat diketahui biaya pemakaian bahan bakar mempunyai pengaruh yang mendominasi terhadap biaya operasional kendaraan. Dari perhitungan koefisien korelasi diperoleh angka koefisien variabel $\mathrm{X}_{1}$ sebesar 0,974 . Maka yang didapat adalah sebagai berikut:

$\mathrm{Y}=11,167+0,974 \mathrm{X}_{1}$

Dari model persamaan tersebut di atas memberi penjelasan jika biaya pemakaian bahan bakar bertambah satu satuan dan juga biaya pemakaian oli mesin bertambah satu satuan, maka perjalanan dalam hal ini merupakan biaya operasionalnya akan mengalami peningkatan sebagai berikut:

$$
\begin{aligned}
\mathrm{Y} & =11,167+0,974 \mathrm{X}_{1} \\
\mathrm{Y} & =11,167+0,974(1) \\
& =\mathrm{Rp} 12,141 \mathrm{Km}
\end{aligned}
$$

\section{Analisis Biaya Operasional (BOK) sepeda motor}

Dari hasil perhitungan Biaya Operasional Kendaraan (BOK) roda dua (sepeda motor) yang telah dilakukan, maka diperoleh jumlah total rata-rata dan jumlah total maksimum biaya operasionalnya tiap 1 (satu) km perjalanannya. Rekapitulasi Biaya Operasional Kendaraan (BOK) total rata-rata yang dikelompokkan berdasarkan jenis, kapasitas dan tahun perakitan kendaraan dilihat pada tabel 4.31 berikut ini.

Tabel 6. Rekapitulasi BOK Total Rata-rata Tiap $1 \mathrm{Km}$

\begin{tabular}{|l|c|c|c|c|}
\hline \multirow{2}{*}{ Uraian/ Tahun Perakitan } & \multicolumn{4}{|c|}{ Kapasitas/Tipe (Rp) } \\
\cline { 2 - 5 } & $\begin{array}{c}100 \\
\text { CC }\end{array}$ & $\begin{array}{r}125 \\
\text { CC }\end{array}$ & $\begin{array}{c}110 \\
\text { CC }\end{array}$ & $\begin{array}{c}115 \\
\text { CC }\end{array}$ \\
\cline { 2 - 5 } & \multicolumn{2}{|c|}{ Bebek } & \multicolumn{2}{c|}{ Skuter Matic } \\
\hline Tahun Perakitan 2004-2009 & & & & \\
\hline Biaya Tetap (FC) & 138,24 & 92,99 & 77,03 & 91,23 \\
\hline Biaya Variabel (VC) & 470,61 & 433,57 & 416,51 & 432,67 \\
\hline Total (FC + VC) & 608,85 & 526,56 & 493,54 & 523,9 \\
\hline Tahun Perakitan 2010-2015 & & & & \\
\hline Biaya Tetap (FC) & - & 91,02 & 151,41 & 143,69 \\
\hline Biaya Variabel (VC) & - & 407,47 & 507,45 & 400,28 \\
\hline Total (FC + VC) & - & 498,59 & 658,86 & 543,97 \\
\hline
\end{tabular}


Vol. 4 No.1 April 2018

pp. 85 - 95

Dari tebel di atas dapat kita simpulkan bahwa besarnya biaya operasional kendaraan bermotor roda dua rata-rata tiap satu kilometer perjalanan di Desa Blang Puuk Kecamatan Seunagan adalah sebagai berikut:

1. BOK rata-rata kepasitas kendaraan $100 \mathrm{CC}$ (jenis bebek) tahun perakitan 2004-2009 yaitu sebesar Rp608,85;

2. BOK rata-rata kapasitas kendaraan 125 CC (jenis bebek) tahun perakitan 2004-2009 dan 2010-2015 yaitu sebesar Rp526,56 dan Rp498,59;

3. BOK rata-rata kapasitas kendaraan 110 CC (jenis skuter matic) tahun perakitan 2004-2009 dan 2010-2015 yaitu sebesar Rp493,54 dan Rp658,86;

4. BOK rata-rata kapasitas kendaraan 115 CC (jenis skuter matic) tahun perakitan 2004-2009 dan 2010-2015 yaitu sebesar Rp523,90 dan Rp543,97;

Sedangkan rekapitulasi Biaya Operasional Kendaraan (BOK) total maksimum yang dikelompokkan berdasarkan jenis, kapasitas dan tahun perakitan kendaraan dapat dilihat pada tabel 4.32 berikut ini.

Tabel 7. Rekapitulasi BOK Total Maksimun Tiap $1 \mathrm{Km}$

\begin{tabular}{|c|c|c|c|c|}
\hline \multirow{3}{*}{ Uraian/ Tahun Perakitan } & \multicolumn{4}{|c|}{ Kapasitas/Tipe (Rp) } \\
\hline & $100 \mathrm{CC}$ & $125 \mathrm{CC}$ & $110 \mathrm{CC}$ & $115 \mathrm{CC}$ \\
\hline & \multicolumn{2}{|c|}{ Bebek } & \multicolumn{2}{|c|}{ Skuter Matic } \\
\hline \multicolumn{5}{|l|}{ Tahun Perakitan 2004-2009 } \\
\hline Biaya Tetap (FC) & 251,89 & 128,4 & 89,82 & 109,9 \\
\hline Biaya Variabel (VC) & 604,86 & 546,38 & 481,06 & 519,7 \\
\hline Total $(\mathrm{FC}+\mathrm{VC})$ & 856,75 & 674,78 & 570,88 & 629,60 \\
\hline \multicolumn{5}{|l|}{ Tahun Perakitan 2010-2015 } \\
\hline Biaya Tetap (FC) & - & 134,76 & 269,31 & 254,33 \\
\hline Biaya Variabel (VC) & - & 470,81 & 725,74 & 508,63 \\
\hline Total $(\mathrm{FC}+\mathrm{VC})$ & - & 605,57 & 995,05 & 762,96 \\
\hline
\end{tabular}

Dari tabel dan diagram batang di atas dapat kita simpulkan bahwa besarnya biaya operasional kendaraan bermotor roda dua maksimum tiap 1 (satu) kilometer perjalanan di Desa Blang Puuk Kecamatan Seunagan adalah sebagai berikut:

1. BOK maksimum kapasitas kendaraan 100 CC (jenis bebek) tahun perakitan 2004-2009 yaitu sebesar Rp856,75;

2. BOK maksimum kapasitas kendaraan 125 CC (jenis bebek) tahun perakitan 2004-2009 dan 2010-2015 yaitu sebesar Rp674,78 dan Rp605,57;

3. Bok maksimum kepasitas kendaraan 110 CC (jenis skuter matic) tahun perakitan 2004-2009 dan 2010-2015 yaitu sebesar Rp570,88 dan Rp995,05;

4. BOK maksimum kapasitas kendaraan 115 CC (jenis skuter matic) tahun perakitan 2004-2009 dan 2010-2015 yaitu sebesar Rp629,60 dan Rp762,96;

\section{Kesimpulan}

Setelah dilakukan perhitungan-perhitungan untuk mendapatkan hasil dan uraian pembahasan mengenai perbandingan biaya operasional kendaraan bermotor roda dua antara matic dan manual di Desa Blang Puuk Kecamatan Seunagan, dapat diambil beberapa kesimpulan yaitu sebagai berikut: 
Vol. 4 No.1 April 2018

pp. 85 - 95

1. Analisis biaya operasional kendaraan dilakukan dengan cara serangkaian pengujian statistik seperti analisis koefisien korelasi, regresi linier berganda, analisa koefisien determinasi $\left(\mathrm{R}^{2}\right)$, uji $\mathrm{t}$ dan uji $\mathrm{F}$ terhadap variabel terikat (dependent) dan variabel bebas (independent). Variabel terikat adalah perjalanan dalam hal ini yang mempengaruhi biaya operasionalnya, sedangkan variabel bebas adalah biaya pemakaian bahan bakar, biaya pelumas (oli mesin dan oli transmisi/gear), biaya pergantian ban (ban luar dan ban dalam), biaya pelaksanaan servis, biaya suku cadang, dan biaya tak terduga. Perhitungan biaya operasional meliputi biaya tetap dan biaya variabel.

2. Model analisis biaya operasional kendaraan di Desa Blang Puuk adalah: $\quad \mathrm{Y}=11,167+$ $0,004 X_{1}+0,001 X_{2}+0,000 X_{3}+0,002 X_{4}-0,003 X_{5}+0,001 X_{6}+0,001 X_{7}+3,905 X_{8}$

3. Faktor yang paling mendominasi yang mempengaruhi biaya operasional di Desa Blang Puuk adalah biaya pemakaian bahan bakar.

4. Biaya Operasional Kendaraan (BOK) rata-rata tiap $1 \mathrm{~km}$ perjalanan di Desa Blang Puuk Kecamatan Seunagan yaitu sebagai berikut:

- BOK rata-rata kepasitas kendaraan 100 CC (jenis bebek) tahun perakitan 2004-2009 yaitu sebesar Rp608,85;

- BOK rata-rata kapasitas kendaraan 125 CC (jenis bebek) tahun perakitan 2004-2009 dan 2010-2015 yaitu sebesar Rp526,56 dan Rp498,59;

- BOK rata-rata kapasitas kendaraan 110 CC (jenis skuter matic) tahun perakitan 20042009 dan 2010-2015 yaitu sebesar Rp493,54 dan Rp658,86;

- BOK rata-rata kapasitas kendaraan 115 CC (jenis skuter matic) tahun perakitan 20042009 dan 2010-2015 yaitu sebesar Rp523,90 dan Rp543,97;

5. Biaya Operasional Kendaraan (BOK) total maksimum dan rata-rata tiap $1 \mathrm{~km}$ perjalanan di Desa Blang Puuk Kecamatan Seunagan yaitu sebagai berikut:

- BOK maksimum kapasitas kendaraan 100 CC (jenis bebek) tahun perakitan 20042009 yaitu sebesar Rp856,75;

- BOK maksimum kapasitas kendaraan 125 CC (jenis bebek) tahun perakitan 20042009 dan 2010-2015 yaitu sebesar Rp674,78 dan Rp605,57;

- Bok maksimum kepasitas kendaraan $110 \mathrm{CC}$ (jenis skuter matic) tahun perakitan 2004-2009 dan 2010-2015 yaitu sebesar Rp570,88 dan Rp995,05;

- BOK maksimum kapasitas kendaraan $115 \mathrm{CC}$ (jenis skuter matic) tahun perakitan 2004-2009 dan 2010-2015 yaitu sebesar Rp629,60 dan Rp762,96.

\section{Saran}

1. Sebagai bahan perbandingan mengenai analisa Biaya Operasional Kendaraan (BOK) roda dua (sepeda motor) sebaiknya dilakukan penelitian serupa untuk daerah lain.

2. Disarankan kepada pengguna sepeda motor untuk memperhatikan faktor merk ataupun jenis sepeda motor dan biaya operasionalnya pada saat ingin membeli kendaraan tersebut, sehingga dapat mempertimbangkan biaya langsung dan tak langsung pada saat memiliki sepeda motor.

3. Diharapkan kepada pengguna sepeda motor untuk dapat memperhatikan ketentuan-ketentuan dalam mengoperasikan kendaraannya sesuai dengan aturan pabrikan sepeda motor tersebut, ataupun sesuai dengan kebijakan daerah setempat. Sehingga tidak terjadi hal-hal yang tidak diinginkan ataupun kerugian yang dapat mempengaruhi biaya operasional kendaraan tersebut. 
Vol. 4 No.1 April 2018

pp. 85 - 95

\section{DAFTAR PUSTAKA}

[1] Amirin, Tantang M. (2011). Populasi dan Ukuran Sampel Rumus Slovin, A blog Of Yogyakarta State-Universitas Blogs, Yogyakarta.

[2] Arifin, (2013). Teknik Sepeda Motor. Jakarta: Bumi Aksara

[3] Bruton, M. J. (1975). Introduction to Transportation Planning, London: Hutchinson \& Co.

[4] Cossalter, Vittore (2006). Motorcycle Dynamics. Lulu. ISBN 978-1-4303-0861-4.

[5] Iqbal, M. 2013, Pengolahan Data dengan Regresi Linear Berganda (dengan SPSS), Jakarta.

[6] Muhazar, (2013). Analisa Model Bangkitan Perjalanan Pada Daerah Relokasi (Studi Kasus Desa Blang Beurandang), Universitas Teuku Umar, Judul Tidak di Publikasi.

[7] Morlok, E. K. (1995). Pengantar Teknik dan Perencanaan Transportasi. Erlangga. Jakarta.

[8] Safrizal, H. (2014). Analisa Model Bangkitan Perjalanan Pada Daerah Relokasi (Studi Kasus Relokasi Desa Pasi Mesjid), Universitas Teuku Umar, Judul Tidak di Publikasi.

[9] Sarwono, J. 2013, 12 Jurus Ampuh SPSS untuk Riset Skripsi, Elexmedia Komputindo Kompas Gramedia, Jakarta.

[10]Sugiyono, 2001. Metoda Penelitian Administrasi dilengkapi dengan Metode R\&D. Alfabeta, Bandung.

[11]Tamin, O.Z. 1997. Perencanaan dan Pemodelan Transportasi, Edisi Pertama, Penerbit ITB, Bandung.

[12]Warsiti, 2003. Analisis Biaya Operasi Kendaraan Bermotor Roda Dua di Semarang, Universitas Diponegoro, Semarang. 